\title{
Prevalence of congenital heart disease in patients undergoing surgery for major gastrointestinal malformations: an Indian study
}

\author{
Rajendra K Gokhroo, ${ }^{1}$ Sajal Gupta, ${ }^{1}$ Garima Arora, ${ }^{2}$ Devendra S Bisht, ${ }^{1}$ \\ Deepak Padmanabhan, ${ }^{1}$ Varsha Soni
}

${ }^{1}$ Department of Cardiology, J.L.N. Medical College, Ajmer, Rajasthan, India

${ }^{2}$ Department of Pediatric Surgery, J.L.N. Medical College, Ajmer, Rajasthan, India

\section{Correspondence to}

Dr Sajal Gupta, Department of Cardiology, J.L.N. Medical College, 22/16, Vaishali Nagar, Ajmer, Rajasthan 305001, India;

drsajal@yahoo.com

Received 29 July 2014 Revised 4 March 2015 Accepted 18 May 2015

\section{ABSTRACT \\ Background The association of congenital heart} disease (CHD) with malformations of the gastrointestinal (GI) tract/abdominal wall is known. The rates of cardiac malformations reported in previous studies of these anomalies are highly variable.

Objective To find the prevalence and pattern of CHD in patients with major gastrointestinal malformations (anorectal malformations, oesophageal atresia/tracheooesophageal fistula, and omphalocoele) undergoing surgery at a tertiary care hospital in India.

Methods From July 2012 to December 2013, 43 patients (34 (79\%) male, 9 (21\%) female) were evaluated by clinical examination, ECG, chest radiography, and colour Doppler echocardiography. Results of the 43 patients, 26 (60.46\%) had CHD. The most common $\mathrm{Gl}$ malformation was anorectal malformation: 32 cases (74.41\%), of whom 16 (50\%) had CHD. The second most common malformation was oesophageal atresia/tracheo-oesophageal fistula: 5 cases $(11.62 \%)$, all (100\%) with CHD. The third group comprised patients with omphalocoele: 4 cases $(9.3 \%)$, 3 of whom (75\%) had CHD. The fourth group comprised patients with VACTERAL (vertebral anomalies, anal atresia, cardiovascular malformations, tracheooesophageal fistula, renal and limb anomalies) association-2 cases (4.6\%), all (100\%) with CHD. The most common CHD was isolated atrial septal defect (ASD) (73\%), followed by ASD + ventricular septal defect (VSD) + patent ductus arteriosus (PDA) (7.6\%), ASD + VSD (3.8\%), ASD + PDA (3.8\%), VSD (3.8\%), PDA (3.8\%), and coarctation of the aorta (3.8\%). Conclusions We found the frequency of CHD in patients with $\mathrm{Gl}$ malformations was very high, the most common presentation being ASD. Our study indicates the need for larger scale studies to determine the prevalence of CHD in patients with $\mathrm{GI}$ malformations in the Indian population.

\section{INTRODUCTION}

The association of congenital heart disease (CHD) with malformations of the gastrointestinal tract (GI)/abdominal wall is known. CHD has been reported in approximately $20 \%$ of patients with major GI malformations without syndromes and in $65 \%$ of patients with GI malformations with recognisable syndromes. ${ }^{1} 2$ The rates of cardiac malformations reported in studies of these anomalies vary greatly.

The VACTERAL (vertebral anomalies, anal atresia, cardiovascular malformations, tracheo-oesophageal fistula, renal and limb anomalies) association is a nonrandom pattern of defects occurring together and includes at least three of the above cardinal features.

The prevalence of GI malformations is 1.3 per 1000 live births. ${ }^{1}$ The frequency of $\mathrm{CHD}$ has been show to be higher in subjects with GI malformations compared to the normal population. ${ }^{1-4}$ Detailed investigation of children with GI malformations for other system malformations is essential for the treatment of these patients, and may be difficult in the presence of a coexisting anomaly. ${ }^{5}$

\section{METHODS}

From July 2012 to December 2013, 43 patients with GI malformations were referred for cardiac evaluation. Physical examination of all patients was undertaken, together with ECG, chest radiography, and colour Doppler echocardiography.

Echocardiography was performed using a Philips iE33 (Philips Ultrasound, USA) machine with 2-7 MHz and 1-12 MHz transducers.

The GI system anomalies were grouped as:

A. Without syndromes: (a) anorectal malformations, (b) oesophageal atresia/tracheo-oesophageal fistula, (c) omphalocoele

B. With syndromes: VACTERAL association.

\section{Statistical analysis}

Data were analysed using SPSS V.10.0 (Chicago, Illinois, USA) for Windows software.

\section{RESULTS}

Of the 43 patients, 34 (79\%) were males and 9 (21\%) were females (table 1). A total 26 patients (60.46\%) had CHD (table 2). The most common GI malformation was anorectal malformation: 32 cases (74.41\%), of whom 16 (50\%) had CHD. The second most common malformation was oesophageal atresia/tracheo-oesophageal fistula: 5 cases (11.62\%), all (100\%) with CHD. The third group comprised patients with omphalocoele: 4 cases (9.3\%), 3 of whom (75\%) had CHD. The fourth group involved patients with VACTERAL association-2 cases $(4.6 \%)$, all $(100 \%)$ with CHD. (table 3).

The most common of the CHDs was isolated atrial septal defect (ASD) (73\%), followed by ASD + ventricular septal defect (VSD) + patent ductus arteriosus (PDA) (7.6\%), ASD + VSD (3.8\%), ASD + PDA (3.8\%), VSD (3.8\%), PDA (3.8\%), and coarctation of the aorta $(3.8 \%)$ (table 3 , figure 1$)$. No patient was found to have cyanotic heart disease. 
Table 1 Demographics of the study population

\begin{tabular}{lll}
\hline & Number $(\mathbf{n}=43)$ & $\%$ \\
\hline Sex & & \\
$\quad$ Males & 34 & 79 \\
$\quad$ Females & 09 & 21 \\
Age & & \\
$<1$ month & 29 & 67.44 \\
1-2 months & 08 & 18.60 \\
2-6 months & 06 & 13.95 \\
\hline
\end{tabular}

Table 2 Prevalence of CHD in the study population

\begin{tabular}{llc}
\hline Patients & Number & $\%$ \\
\hline CHD & 26 & 60.46 \\
Normal & 17 & 39.54 \\
Total & 43 & 100 \\
\hline
\end{tabular}

CHD, congenital heart disease.

\section{DISCUSSION}

It has long been recognised that there is an association between major GI malformations and CHD. Although the frequency of $\mathrm{CHD}$ in the general population is $<1 \%$, it is in the range of $16.5-28.5 \%$ in patients with GI malformations, ${ }^{2} 367$ and as high as $65 \%$ in those GI malformations cases accompanied by syndromes. ${ }^{1}$ In a study by Tulloh et al, ${ }^{4}$ about $20 \%$ of patients with major GI malformations had an associated CHD. Chéhab et $a l^{8}$ from Lebanon reported the occurrence of congenital cardiac anomalies in 38\% of 105 patients with GI malformations. In our study, we found the prevalence of CHD was $60.46 \%$ in our patients with GI malformations.

Previous studies ${ }^{9}$ have found VSD to be the most common CHD in patients with GI malformations/VACTERAL association, but in our Indian population we found ASD to be more common. Our findings are in agreement with those of a recent study by Örün et al, ${ }^{10}$ where the order of frequency of cardiac defects in 242 patients with GI malformations was: 31 (44.9\%) with ASD, 17 (24.6\%) with VSD, 5 (7.2\%) with PDA, 3 with ASD + VSD + PDA, 2 with isolated dextrocardia, and 2 with aortic stenosis. Also ASD + VSD, ASD + VSD + pulmonary stenosis, PDA + pulmonary stenosis, tricuspid atresia, pulmonary stenosis, ASD, coarctation of the aorta, tetralogy of Fallot, and transposition of the great arteries were each observed in one patient. The reason why ASD is the most common presentation in the Indian population is to be evaluated on a genetic/environmental/ethnicity basis in future large scale studies of such patients.

Olgun $e t a l^{2}$ reported the rate of CHD in patients with imperforate anus, omphalocoele, oesophageal atresia/tracheo-oesophageal fistula, and diaphragmatic hernia, as 15.9\%, 28.6\%, 23.7\%, and $8 \%$, respectively. Thompson et $a l^{1}$ reported CHD rates of $23 \%$, $19 \%, 12 \%$, and $17 \%$, respectively, in the same patient groups. In our study, CHD rates in patients with anorectal malformations, oesophageal atresia/tracheo-oesophageal fistula, and omphalocoele were $50 \%, 100 \%$, and $75 \%$, respectively.

In the present study, in a subgroup of anorectal malformations the CHD rate was found to be $50 \%$, with ASD being the most common followed by VSD and PDA. In a study where the CHD rate in patients with anorectal malformations was $22 \%$, VSD was found to be the most frequent CHD. ${ }^{9}$ In another study involving 103 patients, the CHD rate was $27 \%$ and VSD, ASD, pulmonary stenosis, and tetralogy of Fallot were the most frequent conditions. ${ }^{5}$ In a study by Voisin et al, ${ }^{11}$ involving patients with anorectal malformation, the incidence of CHD was 9-14\%, with a predominance of VSD and tetralogy of Fallot. A study in Iran revealed an incidence rate of congenital cardiac anomalies of $50.4 \%$ in newborns with imperforate anus. ${ }^{12}$

The risk of CHD is high among oesophageal atresia/ tracheo-oesophageal fistula patient groups. Although all CHDs may occur in patients with oesophageal atresia/tracheooesophageal fistula, VSD, PDA, and ASD are the most frequent. $^{5} 1314$ In the present study, ASD followed by VSD and PDA were the most frequent anomalies in the oesophageal atresia/tracheo-oesophageal fistula patients.

The reason for the high frequency of CHD in patients of GI malformation has not been fully established. The early failure of midline mesodermal embryogenesis is the most popular theory for this association. The embryological period during which the caudal end of the fetus is differentiated (5-24 weeks) is also the time when many other body systems develop. It is likely that an embryological defect occurring at this time, leading to anorectal malformation, would also cause a high incidence of other anomalies. The reasons to look for these anomalies are: (1) priority of management, for example, oesophageal atresia has priority of treatment over anorectal malformation; (b) a severe cardiac anomaly may preclude successful treatment; and (c) associated anomalies may themselves have a bearing on the ultimate outcome.

The recognition of a cardiac lesion in this group of patients is important, particularly in those with associated syndromes. Association of CHD may increase the mortality. In one study, deaths were considered to be directly related to the heart lesion in infants with imperforate anus, omphalocoele, and oesophageal atresia with $\mathrm{CHD}$, and the reported death rates were $72.7 \%, 20 \%$, and $10 \%$, respectively. ${ }^{2}$

Table 3 Frequency of CHD in the study population

\begin{tabular}{|c|c|c|c|c|c|c|c|c|c|c|}
\hline GI malformation & CHD & Percentage of CHD & ASD & VSD & PDA & $A S D+V S D$ & ASD+PDA & $A S D+V S D+P D A$ & $\mathrm{COA}$ & Norma \\
\hline ARM $(N=32)$ & 16 & $50 \%$ & 12 & 1 & 1 & 1 & - & - & 1 & 16 \\
\hline OA/TOF $(\mathrm{N}=5)$ & 5 & $100 \%$ & 3 & - & - & - & 1 & 1 & - & \\
\hline Omphalocoele $(\mathrm{N}=4)$ & 3 & $75 \%$ & 2 & - & - & - & - & 1 & - & 1 \\
\hline VACTERAL association ( $\mathrm{N}=2$ ) & 2 & $100 \%$ & 2 & - & - & - & - & - & - & \\
\hline $\mathrm{N}=43$ & 26 & $60.46 \%$ & 19 & 1 & 1 & 1 & 1 & 2 & 1 & 17 \\
\hline
\end{tabular}

ARM, anorectal malformation; ASD, atrial septal defect; CHD, congenital heart disease; CoA, coarctation of aorta; OA/TOF, oesophageal atresia/tracheo-oesophageal fistula; GI, gastrointestinal; PDA, patent ductus arteriosus; VACTERAL, vertebral anomalies, anal atresia, cardiovascular malformations, tracheo-oesophageal fistula, renal and limb anomalies; VSD, ventricular septal defect. 


\section{PERCENTAGE}

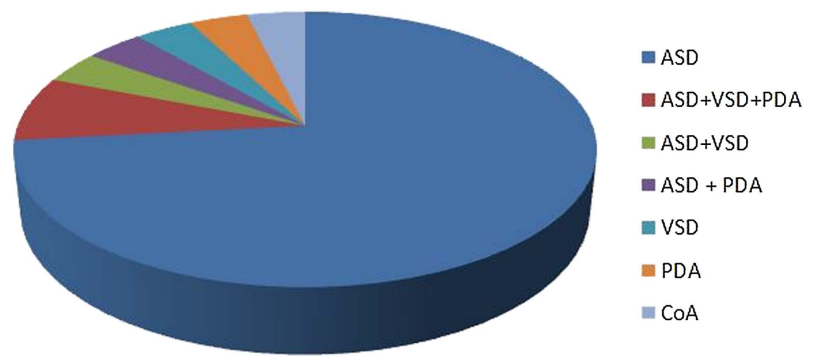

Figure 1 Distribution of congenital heart disease in the study population. ASD, atrial septal defect; CoA, coarctation of the aorta; PDA, patent ductus arteriosus; VSD, ventricular septal defect.

Before embarking on major surgery, it is important to be aware of the infant's cardiac status, both for prognostic purposes and to provide sub-acute bacterial endocarditis prophylaxis, if appropriate. There is a need to counsel patients about the risk of future pregnancies. An echocardiogram should be performed in these patients as a matter of routine during clinical examination.

\section{Study limitations}

1. The study includes a small number of patients, so the power of the study is lower.

2. Long term follow-up of patients was not done.

3. Some patients with very severe GI malformations, for example, oesophageal atresia, who died soon after birth, could not be screened.

\section{CONCLUSION}

Our study is one of the few studies to assess the prevalence of CHD in patients with GI malformations in India. To the best of our knowledge, it is the only study to determine the pattern of CHD. The frequency of CHD in GI malformations patients was found to very high, and ASD to be the most common CHD. Our study indicates the need for larger scale studies to determine the prevalence of CHD in patients with GI malformations in the Indian population, both for prognostic purposes and to provide sub-acute bacterial endocarditis prophylaxis if required. Early diagnosis of CHD will allow a unified approach to be presented to the family.

Contributors RKG provided the concept for the manuscript, performed the procedures and analysed the data. SG performed the review, acquired the data, and wrote the manuscript. GA provided the design of study, the definition of intellectual content, data analysis and manuscript editing. DSB, DP and VS were responsible for the literature search, data acquisition, statistical analysis and editing of the manuscript.

Competing interests None declared.

Provenance and peer review Not commissioned; externally peer reviewed.

\section{REFERENCES}

1 Thompson AJ, Mulholland HC. The incidence of cardiac lesions in infants born with major gastrointestinal malformations in Northern Ireland. Ulster Med J 2000;69:23-6.

2 Olgun $\mathrm{H}$, Karacan $\mathrm{M}$, Caner I, et al. Congenital cardiac malformations in neonates with apparently isolated gastrointestinal malformations. Pediatr Int 2009:51:260-2.

3 Wojtalik M, Mrowczynski W, Henschke J, et al. Congenital heart defect with associated malformations in children. J Pediatr Surg 2005;40:1675-80.

4 Tulloh RM, Tansey SP, Parashar K, et al. Echocardiographic screening in neonates undergoing surgery for selected gastrointestinal malformations. Arch Dis Child Fetal Neonatal 1994;70:206-8.

5 Cho S, Moore SP, Fangman T. One hundred three consecutive patients with anorectal malformations and their associated anomalies. Arch Pediatr Adolesc Med 2001;155:587-91.

6 Ein SH, Shandling B, Wesson D, et al. Esophageal atresia with distal tracheoesophageal fistula: associated anomalies and prognosis in the 1980s. J Pediatr Surg 1989;24:1055-9.

7 Hassink EA, Rieu PN, Hamel BC, et al. Additional congenital defects in anorectal malformations. Eur J Pediatr 1996;155:477-82.

8 Chéhab G, Fakhoury H, Saliba Z, et al. Congenital heart disease associated with gastrointestinal malformations. J Med Liban 2007;55:70-4.

9 Teixeira $\mathrm{OH}$, Malhotra K, Sellers J, et al. Cardiovascular anomalies with imperforate anus. Arch Dis Child 1983;58:747-9.

10 Örün UA, Bilici M, Demirçeken FG, et al. Gastrointestinal system malformations in children are associated with congenital heart defects. Anadolu Kardiyol Derg 2011;1:146-9.

11 Voisin M, Galifer RB, Kadiri T, et al. Intestinal malformations and congenital heart disease. Arch Mal Coeur Vaiss 1987;80:524-8.

12 Abadi SA, Abadi NA, Mashrabi 0, et al. Congenital heart anomalies in babies with imperforate anus and its motility. Res J Biol Sci 2008;3:922-4.

13 David TJ, O'Callaghan SE. Cardiovascular malformations and oesophageal atresia. Br Heart J 1974;36:559-65.

14 German JC, Mahour GH, Woolley MM. Esophageal atresia and associated anomalies. J PediatrSurg 1976;11:299-306. 